\title{
A educação infantil no Brasil: desenvolvimento e desafios ao longo da história
}

Simone Oliveira de Andrade Silva

Doutoranda do programa de pós-graduação stricto sensu em Educação: Psicologia da Educação, da Pontifícia Universidade Católica de São Paulo

E-mail:monemestre@gmail.com
Resumo: Este artigo apresenta um levantamento histórico do atendimento à criança em idade não escolar no Brasil, abordando tanto as políticas públicas para a infância como os movimentos populares e de iniciativa privada. A intenção é mostrar não só os conflitos que existiram, e ainda existem, mas os avanços e conquistas. Além disso, para que se compreenda o porquê da dicotomia entre o Centro de Educação Infantil (CEI) e a Escola Municipal de Educação Infantil (Emei em São Paulo, SP), é preciso conhecer como cada uma delas se constitui antes de ser agrupadas em um mesmo sistema de ensino. Para isso foram utilizados documentos oficiais e a literatura bibliográfica pertinente. 0 que se pretendeu foi descrever a evolução histórica e os embates e consensos produzidos pelo poder público, a sociedade civil e o meio acadêmico durante esse processo.

Palavras-chave: Educação infantil. Criança. Políticas públicas. Educação. 
A educação infantil tem sido alvo de atenção na atualidade. Estudos realizados por Taggart et al. (2011), Campos et al. (2011a), Curi e Menezes (2006) e MEC e UFRGS (2009) têm comprovado a importância desse nível de ensino no desempenho da criança em sua escolaridade posterior. Os resultados indicam que tem ficado evidente seu valor, mostrando seu impacto no campo da aprendizagem.

A pesquisa longitudinal realizada por Taggart et al. (2011) na Inglaterra acompanhou mais de 3 mil crianças da pré-escola até os 11 anos, em grupos divididos por crianças que:

- não frequentaram nenhum tipo de educação formal;

- frequentaram recreação infantil;

- frequentaram algum tipo de educação formal ${ }^{1}$.

Entre os resultados obtidos, identificou-se que a

[...] frequência à pré-escola quando comparada a não frequência a ela, favorece o desenvolvimento cognitivo e sociocomportamental [...] A pré-escola de melhor qualidade está associada a melhores resultados das crianças [...] (TAGGART et al., 2011, p. 81-82).

Em nível nacional, a pesquisa de Campos et al. (2011a) apresentou a importância da El. Os autores avaliaram que uma educação de qualidade, já nos primeiros níveis de educação, pode promover melhora no desenvolvimento das crianças:

A literatura especializada reconhece que a criança se beneficia, tanto no presente como em sua escolaridade futura, da oportunidade de acesso à EI, e esses efeitos são tão mais positivos quanto melhor a qualidade dessa educação e são mais significativos para as crianças mais pobres (p. 29).

Reafirmando a importância da educação infantil na continuidade dos estudos da criança, Campos et al. (2011b) continuaram:

As crianças que têm a oportunidade de frequentar uma boa instituição de educação infantil contam com maior probabilidade de obter bons resultados no ensino fundamental, como mostram pesquisas recentes nacionais e internacionais (p.27).

Mas a compreensão das conquistas historicamente alcançadas na luta por uma educação infantil de qualidade deve ser afirmada quando se analisa o seu percurso no Brasil, sob o risco de apresentar discursos abstratos, que não se enraízam nas disputas vivenciadas por grupos que defendem o atendimento da criança deste nível de educação, como afirma Campos (1999). A autora relata que:

As crianças avaliadas pelo estudo que frequentaram educação formal (pré-escolas) foram divididas nos seguintes grupos: as que frequentaram centros de educação, as que frequentaram pré-escolas privadas, as que frequentaram pré-escolas mantidas pelo governo e as que frequentaram pré-escolas do governo. 
Talvez uma das razões que contribuam para esta dificuldade seja o fato de que as prescrições legais, assim como as pedagógicas, apareçam para a maioria das pessoas como destituídas de história, deduzidas de princípios abstratos e não como conquistas que decorrem de longas e penosas disputas na sociedade, vividas por pessoas de carne e osso

Na presente descrição, percorreu-se o caminho da educação infantil no Brasil, considerando os movimentos de grupos sociais, acadêmicos e públicos, bem como as políticas que a conduziram. A intenção é relatar os debates, as conquistas e as transformações que ocorreram ao longo dos anos.

\section{A EDUCAÇÃO INFANTIL E AS POLÍTICAS PARA A INFÂNCIA NO BRASIL}

0 atendimento à criança no Brasil não teve uma origem precisa, tendo surgido em várias frentes: pública, privada, filantrópica e comunitária. De acordo com Barreto (1998), é possível encontrar registros dessas iniciativas que datam de mais de cem anos. No entanto, somente em 1934 configurou-se o primeiro direito garantido em lei, quando funcionárias mães tiveram assegurada a creche no local de trabalho, conquista esta confirmada pela Consolidação das Leis do Trabalho (CLT), segundo Campos (1999). Esta lei traz, no art. 389, a obrigação de que os

[...] estabelecimentos em que trabalharem pelo menos trinta mulheres, com mais de dezesseis anos de idade, a dispor de local apropriado em que seja permitido às empregadas guardar, sob vigilância e assistência, os seus filhos no período de amamentação (CAMPOS,

1999, p. 120).

Nessa mesma década, mais precisamente em 1931, por meio da Cruzada Pró-Infância, liderada por Pérola Byington, foram criados os parques infantis, cujo programa consistia em assistir crianças de 3 a 7 anos com higiene, saúde e educação (esta última ligada à moral, civismo e bons costumes). Em seu quadro de funcionários havia pediatras, sanitaristas, enfermeiras e cuidadoras.

Em 1935, o governo federal assumiu os parques, tornando-os oficiais e públicos. O programa tinha a concepção de formação de novos cidadãos brasileiros, portanto, o atendimento era direcionado para as crianças das classes operárias e suas famílias (FILÓCOMO, 2005). Os parques infantis tinham função mais social do que educacional, o que lhes renderia futuras críticas e sua substituição por modelos mais escolarizados (SOUZA, 2012).

Por meio dessas iniciativas, a assistência à criança pequena nos campos trabalhista e social continuava crescendo no país, enquanto que no campo 
educacional ainda davam-se os primeiros passos.

Já na década de 1960, com a procura cada vez maior por vagas para esta faixa etária, surgiram várias modalidades de atendimento, tanto nas instâncias públicas quanto privadas e filantrópicas, com diferentes denominações (creches, parques infantis, jardins de infância, escolas maternais, préescolas). Esses estabelecimentos se espalhavam pelo país, tendo pouca ou nenhuma supervisão dos órgãos públicos competentes.

A partir da década de 1970, esse atendimento começava a se delimitar com o aumento das pesquisas voltadas à criança, que deram origem, entre outras coisas, à proposta de educação compensatória. Sob esse ponto de vista, os estudos indicavam que a educação pré-escolar poderia, de fato, influenciar a diminuição da evasão e da repetência escolar, por trazer uma estimulação educacional que o ambiente familiar das crianças pobres não proporcionava. A partir dessas descobertas, os governos federal, estaduais e municipais deram início à expansão do atendimento à criança pequena nos sistemas de educação pública. Esse novo tipo de escola mantinha o modelo da educação formal, o que diminuía os custos, pois os parques infantis necessitavam de espaços amplos para as variadas atividades, enquanto que este necessitava somente de salas de aula para seu atendimento.

Neste momento, aumentaram as críticas quanto aos parques infantis, pois se considerava que eles eram estritamente assistenciais e que não ajudavam as crianças em suas dificuldades de aprendizagem. Para os críticos, as famílias das classes populares necessitavam de um espaço onde seus filhos pudessem ser preparados para o ingresso na educação. Com isso, os parques infantis foram substituídos por escolas de educação infantil com cunho preparatório para o então denominado primeiro grau.

Em São Paulo, com a municipalização da educação infantil na década de 1980, o governo municipal iniciou a educação pré-escolar denominada Escola Municipal de Educação Infantil (Emei), com atendimento para crianças de 4 a 6 anos. A Emei surgiu com a tríplice finalidade de educar, assistir e recrear, embora sua ênfase, na prática, tenha sido a preparação para a primeira série. Nesses estabelecimentos, os professores estavam engajados na pré-alfabetização das crianças. O atendimento visava suprir "carências" e deficiências de crianças das classes menos favorecidas, para diminuir os índices de repetência na primeira série; essa modalidade de ensino ficou conhecida popularmente como prézinho. 
Paralelamente a esses esforços do poder público, em outros espaços o atendimento assistencial continuava a crescer, principalmente em creches comunitárias. Estas foram incentivadas, no final da década de 1970, pelo Fundo das Nações Unidas para a Infância (Unicef) e implantadas na década de 1980 pelos movimentos sociais (dentre eles, as associações de moradores de bairro).

Diante da realidade apresentada, os movimentos sindicais e populares, que já estavam em atividade, ganharam como aliado o movimento feminista ainda na década de 1970. Este grupo lutava por vagas em creches na rede pública e pela garantia, além da inserção da mulher no mercado de trabalho, de sua participação política. Essa luta ampliou-se na década de 1980.

A partir de então, as instituições filantrópicas e/ou confessionais e comunitárias se espalharam por todo o território nacional. Mas não foram suficientes para cobrir a demanda existente, o que levou ao surgimento das creches caseiras, cujo atendimento era feito na casa de uma das mães vizinhas. Esta se encarregava de cuidar dos filhos das outras enquanto elas iam trabalhar. Esse tipo de atendimento clandestino, sem nenhuma orientação, seguia o modelo familiar de cuidado da criança. Isso também pode ser observado nos espaços autorizados por convênio com o Estado (KRAMER, 2006). 0 que também não era diferente do serviço prestado nas creches públicas, que tinham como cuidadoras as mães crecheiras, sem nenhuma formação específica. Kuhlmann Jr. (2005) faz uma crítica a esta situação, lembrando a ideia da época, que mantinha uma concepção de atendimento mais barata à infância pobre, conhecida como “[...] políticas das instituições de baixo custo, de baixa qualidade, que invertem ideias. Diziam que bastava uma mãe voluntária trabalhar com as crianças” (KUHLMANN JR., 2005, p. 6).

Ao mesmo tempo, o poder público tentava suprir a falta de vagas e buscava justificar a necessidade de aumento dos subsídios governamentais, o que era francamente criticado por grande parte dos acadêmicos, que estavam preocupados com a alfabetização das crianças maiores e não concordavam com os gastos que poderiam ser deslocados das escolas alfabetizadoras.

Neste campo de luta pela infância no Brasil, somente com a Constituição Federal Brasileira, em 1988 (BRASIL, 1988), a criança de 0 a 6 anos passou a ser vista como sujeito de direitos, sendo garantido por lei o direito a todas as crianças de frequentar as instituições educacionais e não somente àquela provinda de família carente. 0 atendimento educacional para essa faixa etária passava a ser um dever do Estado, um direito da criança e uma opção da 
família. Foi iniciada uma mudança no foco de atendimento, indo em direção ao atendimento à criança, independentemente de sua condição social.

Novas conquistas foram alcançadas, quando, em 1990, foi promulgada a Lei 8.069/90, o Estatuto da Criança e do Adolescente (ECA), que previa, entre outras coisas, que “[...] é dever do Estado assegurar [...] atendimento em creche e pré-escola às crianças de zero a seis anos de idade [...]" (BRASIL, 1990, art. 54, IV).

A partir desses avanços, os debates e discussões sobre a qualidade das escolas de educação infantil no Brasil ganharam destaque, pois as condições da maioria dos estabelecimentos eram precárias e não havia critérios quanto à qualificação dos profissionais de atuavam diretamente com as crianças. A luta que se iniciava agora era por melhoria dos espaços físicos e qualificação profissional dos cuidadores.

Neste momento, também os meios acadêmicos começaram a se preocupar e a lutar pelo atendimento educacional de qualidade à criança pequena (CAMPOS, 1999). A educação infantil passou, então, a ter a atenção cada vez maior de educadores e pesquisadores da área, o que levou à ampliação dos fóruns de discussões sobre a temática por todo o Brasil, pois havia a preocupação de que, com a baixa qualidade nos serviços oferecidos à infância, a criança pequena estivesse ameaçada de prejuízos no seu desenvolvimento.

Diante de todo esse fervilhar de debates e disputas pela garantia dos direitos da criança, na década de 1990, a promulgação da Lei de Diretrizes e Bases da Educação Nacional (LDB) 9.394/96 trouxe à tona outro tópico que polarizou os estudos e debates, reforçando o que indicava a Constituição Federal. Esta lei definia o atendimento à criança de 0 a 6 anos como educacional, passando a caracterizá-lo como a primeira etapa da educação básica (BRASIL, 1996, art. 29 e 30). Seguindo os avanços apresentados na nova LDB, o documento apontou, ainda, as novas exigências quanto à formação dos profissionais que atendiam diretamente a criança pequena. Esta deveria ser em nível superior, sendo aceitos os cursos de Pedagogia ou Normal Superior, admitindo-se a formação mínima em magistério, em nível médio (BRASIL, 1996, art. 31).

A partir desta lei, as creches deveriam, então, migrar da Secretaria de Assistência Social para os sistemas municipais de educação. Essa orientação gerou resistências, discussões e divergências. Isso ocorreu porque, de um lado, as instituições que atendiam em regime de creche possuíam grande conhecimento quanto à atenção e cuidado a esta faixa etária - embora com 
pouca experiência quanto à área pedagógica - e não concordavam com a inserção das creches na educação, sob o risco de escolarização precoce da criança. Do outro lado, as pré-escolas que tinham uma considerável experiência na área pedagógica de trabalho com a criança pequena (mas pouquíssimo conhecimento das especificidades e cuidados da criança desta faixa etária), estavam preocupadas com a desvalorização dos profissionais e dos ambientes educacionais, que poderiam se transformar em espaços assistenciais.

Foi nesse contexto conflituoso que os estudiosos da área alertaram para a dicotomia que se apresentava entre o cuidado e a educação, ou seja, o distanciamento entre creches e pré-escolas. Suas pesquisas apontavam ainda que o atendimento oferecido à criança em creche era precário e de cunho assistencial, tendo como prioridade o cuidado das crianças advindas das classes menos favorecidas, geralmente oferecido por instituições de cunho filantrópico, enquanto que o atendimento educacional realizado nas pré-escolas públicas, ou seja, em ambientes escolares que contavam com mais recursos, era mais preparatório para a escolarização posterior. Essa forma de pensamento, segundo Araújo (2010), não está de todo superada, ela

Ainda é corrente, tanto por parte dos professores como da sociedade em geral, uma visão equivocada em relação à Escola de Educação Infantil [...] de caráter preparatório à primeira série e/ou ainda com uma intensa função, na maioria das situações, assistencialista [...] (ARAÚJO, 1998, p. 14 apud ARAÚJO, 2010, p. 149).

Embora não exista unanimidade para a explicação dessa dicotomia, segundo Kuhlmann Jr. (2005), existem mais questões a serem observadas do que a visão simplista que diferencia o assistencialismo e o educacional do que somente o espaço físico ou administrativo. 0 autor informa que pesquisas atuais já vêm mostrando que nesses ambientes assistenciais também havia educação - a diferença estava no público que era atendido e não no tipo de estabelecimento. A dicotomia estava entre um atendimento assistencial para as crianças de baixa renda e educacional para as crianças das classes altas.

É nesse espaço de turbulência de acontecimentos e renovações na educação infantil que foi divulgado o Referencial Curricular Nacional para a Educação Infantil (RCNEI), em 1998, e encaminhado a todas as escolas desta modalidade. Ele foi denominado como documento orientador das práticas educativas e sua intenção era harmonizar conflitos gerados pela junção dessas duas

ARAÚJO, E. S. Matemática e formação em educação infantil: biografia de um projeto. 1998. Dissertação (Mestrado em Educação) - Faculdade de Educação, Universidade de São Paulo, São Paulo, 1998. 
modalidades de atendimento e ajudar as escolas, instituições públicas ou privadas, na elaboração de seus planejamentos pedagógicos.

Referencial Curricular nacional para a Educação Infantil: um DOCUMENTO UNIFICADOR?

O interesse em debater uma Política Pública Curricular para a Educação Infantil teve início com os encaminhamentos sobre a universalização do ensino. As discussões a respeito de um currículo e diretriz nacionais ganhou força quando, na

[...] reunião de Jomtiem, Tailândia, organizada pela UNESCO em 1990, os países participantes, entre os quais o Brasil, assumiram compromissos em relação a diversas metas educacionais, como a universalização do Ensino Fundamental (CAMPOS, 1998, p. 35).

A partir deste momento, iniciaram-se os estudos e a elaboração do material para a formulação das Diretrizes Curriculares Nacionais dos Ensinos Fundamental e Médio que, em 1997, deram origem ao conjunto de livros conhecidos como Parâmetros Curriculares Nacionais.

Ao mesmo tempo, o Ministério da Educação (MEC) iniciou, em 1994, um amplo processo de discussão sobre este nível de educação no país, com a coordenação geral de Ângela Maria Rabelo Ferreira Barreto. O MEC tinha a intenção de abrir espaço para a discussão e produção de material, a fim de se alcançar uma política de infância nacional que conduzisse para um melhor atendimento, sendo observadas as especificidades desta faixa etária.

Para Palhares e Martinez (2005), este foi um período de muita produção e aprendizagem. De acordo com os autores, esse espaço foi compartilhado por todos aqueles que estavam comprometidos com a educação infantil no país, tanto os acadêmicos como os movimentos populares, as instituições filantrópicas, enfim, todas as pessoas que lutavam pelo cumprimento dos direitos constitucionais da criança e por políticas que apontassem para um atendimento mais digno em todo o território nacional. 0 objetivo inicial do MEC se realizava, pois a produção de documentos, seminários, debates que contribuíram para um amadurecimento do trabalho que já vinha sendo realizado no Brasil ajudou a refletir melhor sobre o que era possível fazer para buscar sua melhoria.

Dentre os objetivos do MEC, estava o que propunha

[...] identificar as propostas existentes e elaborar uma metodologia de análise de propostas, que subsidiasse estados e municípios a empreenderem suas próprias análises de concepção das propostas e da sua implementação (KRAMER, 1999, p. 5). 
Esses espaços de debate ganharam força com a promulgação da LDB 9.394/96, que vinha confirmar o que já havia sido considerado na Constituição Federal de 1988, ao apontar que os estabelecimentos de atendimento à criança pequena deveriam garantir o desenvolvimento integral da criança, numa dimensão tríplice: o educar, o brincar e o cuidar. E, ainda, a lei instituía que as creches deveriam fazer parte do sistema de ensino dos municípios.

No entanto, o processo de discussão iniciado pelo próprio MEC, que vinha sendo elogiado tanto pela academia quanto pelos movimentos sociais, e que estava apresentando grandes resultados, foi interrompido e a equipe foi desfeita. Para Kramer (1999), isso ocorreu pelo fato de, neste grupo de estudo,

[...] o enfoque teórico-metodológico sobre currículo ou proposta curricular, a visão sobre política pública e o papel do Ministério [...] situava-se na direção oposta à do próprio MEC, comprometido com a definição de parâmetros curriculares para todos os niveis de ensino da educação básica.

A nova equipe, que se seguiu a esta primeira, iniciou a elaboração de um documento sem a participação da sociedade civil, e assim, em 1998, concluiu a redação da primeira versão do que foi intitulado RCNEl.

Na tentativa de imprimir ao documento a ideia de amplo debate nacional e garantir a sua aceitação, logo após a conclusão do texto, em 1998, o MEC o enviou a 700 profissionais que estavam de alguma forma ligados à educação infantil, para os quais pediu que emitissem o seu parecer acerca do mesmo, num espaço curto de menos de um mês. Desse total, somente 230 pareceres foram encaminhados para o MEC, os quais apontaram para o avanço na iniciativa de elaborar diretrizes curriculares, mas também apresentaram críticas ao texto, que precisariam ser corrigidas (CERISARA, 2005).

A Associação Nacional de Pós-Graduação e Pesquisa em Educação (Anped) também encomendou a alguns acadêmicos - entre os quais alguns eram pareceristas do MEC - textos sobre o RCNEI e, ao final, elaborou um parecer único que foi encaminhado ao MEC. Neste parecer, foram levantadas questões que precisavam ser revistas antes da divulgação do documento, entre elas, às relacionadas à forma e à estrutura geral do documento. 0 texto trazia sugestões quanto aos aspectos formais, aspectos relativos aos "conteúdos" e aspectos estruturantes da proposta, conforme apontado a seguir: 


\section{- Aspectos formais}

Nossa sugestão é que seja feita uma cuidadosa revisão do texto por pessoas que dominem também seu conteúdo, pois uma revisão gramatical por si só não dará conta dos diversos problemas encontrados por todos aqueles que leram cuidadosamente o documento (ANPED, 1998, p. 91).

\section{- Aspectos relativos aos itens de "conteúdo":}

[...] a abordagem geral adotada, a qual reproduz a estrutura de ensino vigente nas etapas posteriores da educação básica, representa um retrocesso em relação ao que já se acumulou de experiência e conhecimento sobre o desenvolvimento das múltiplas linguagens da criança (ANPED, 1998, p. 96).

- Aspectos estruturantes da proposta:

- Organização por faixas etárias:

[...] a divisão adotada para as faixas etárias é pouco clara: 0 a 3 anos e 3 a 6 anos. Embora essa imprecisão possa parecer um problema menor, [...] seria importante justificar melhor a forma como se concebe essa passagem entre as duas subfaixas etárias (ANPED, 1998, p. 92).

- Concepção de desenvolvimento infantil: “[...] primeira questão diz respeito ao evidente viés psicologizante que transparece no texto" (ANPED, 1998, p. 93).

\section{- Concepção de currículo:}

Muitos comentaristas identificaram a origem do modelo de currículo adotado da proposta desenvolvida para o sistema educacional espanhol. Entretanto, vários leitores apontaram para o fato de o Referencial parecer ter adotado uma concepção pedagógica para a educação infantil mais rígida e conforme uma visão tradicional de ensino do que aquela preconizada nos documentos espanhóis. Mais ainda, ao não contextualizar a contribuição da proposta espanhola, explicitando sua grande influência no documento, não se dá plenas condições ao leitor para uma opção consciente por essa ou outra linha teórica e metodológica (ANPED, 1998, p. 94).

Quanto à influência na concepção de currículo, como apontado pela Anped (1998), a base curricular apresentada foi inspirada na proposta curricular espanhola, o que pode ser confirmado por várias das expressões presentes no documento que acompanham o modelo espanhol, como afirma a pesquisadora Haddad (1998):

Apesar do documento não explicitar a(s) fonte(s) de inspiração para a formulação da estrutura curricular para a educação infantil, é possível identificá-la no documento Diseño Curricular Base: Educación Infantil, publicado em conjunto com o Libro Blanco para la Reforma del Sistema Educativo pelo Ministério de Educação e Ciência da Espanha, no início da década de 90 (Espanha, s/d, a e b), em que se localizam várias expressões adotadas no RCN, tais como: "intencionalidade educativa”, "âmbitos de experiência”, "orientações didáticas”, “aprendizagens significativas", "blocos de conteúdos: conceituais, procedimentais e atitudinais" etc. (HADDAD, 1998, p. 9-10, grifos do autor). 
Após o recebimento e análise desses pareceres pelo MEC, este realizou algumas das alterações propostas no RCNEl e o enviou, ainda em 1998, a todas as escolas de El e creches do país, mesmo antes da elaboração das Diretrizes Curriculares Nacionais para a Educação Infantil, que só em 1999 foram instituídas (com caráter mandatório) pelo Conselho Nacional de Educação (CNE), através da resolução CEB 01/1999 (BRASIL, 1999).

Campos (2002) relata as diferentes influências no documento, que vão desde sua rápida elaboração e divulgação à pressão de grupos nacionais e internacionais, como a Organização das Nações Unidas para a Educação, a Ciência e a Cultura (Unesco), a Comissão Econômica para a América Latina e o Caribe (Cepal) e Banco Mundial, que exigiram uma política do governo federal.

Nesse contexto, o RCNEI, nascido nesse processo contraditório e procurando harmonizar, pelo menos em parte, os conflitos sobre como orientar a educação infantil no Brasil, tornou-se o primeiro documento federal que organizou um currículo nacional para esta modalidade de educação, fazendo parte do conjunto de documentos elaborados para orientar a educação no Brasil. Na leitura do documento, observa-se o registro de sua intenção em uniformizar 0 atendimento às crianças de 0 a 6 anos, elaborando um currículo comum com base em uma concepção de criança, educação infantil e a tríade educar, cuidar e brincar.

De acordo com o MEC, o documento consistiu em

[...] um esforço para estabelecer parâmetros e referências para a Educação Infantil no Brasil [e, ainda,] a importância maior do Referencial foi ter colocado em discussão a questão do currículo para a EI (BRASIL; TV ESCOLA, 2012).

Para Cerisara (2002), o documento foi elaborado em meio a discussões sobre a qualidade da educação infantil que ainda não estavam finalizadas. Ela considera que ainda não era o momento de lançar diretrizes curriculares, pois havia muitos questionamentos quanto ao quê, como e para quê educar nessa faixa de idade. A autora afirma que, quando o RCNEl foi divulgado, a educação estava ainda recebendo essas crianças como parte integrante da educação básica e, além do mais, a sociedade ainda estava tentando entender como isso deveria ser organizado.

Apesar de todas as controvérsias apontadas, a caracterização da educação infantil como primeira etapa da educação básica e a elaboração de um documento que visa orientar os seus estabelecimentos foram consideradas um avanço na busca de qualidade para o atendimento da criança pequena, 
haja vista a pouca produção de material educacional e de pesquisa na área pedagógica na época, o que pode garantir sua utilização, como afirmou Araújo (2010), ao abordar o seu uso no país. Para ela

Seu uso é frequentemente justificado porque, apesar das inúmeras críticas ao RCNEI, este pode ser, de certa forma, considerado um avanço, por tratar-se de um documento que se diz voltado especificamente para a Educação Infantil [...] ele foi uma primeira tentativa de conferir uma sistematização curricular à Educação Infantil, mérito que não pode ser desprezado (ARAÚJO, 2010, p. 139).

A Anped, no parecer emitido sobre o RCNEI, não desconsiderou seu valor de ser um documento orientador das práticas pedagógicas, ao concluir que

Acreditamos que essa iniciativa do MEC deverá ter um grande impacto nas creches e préescolas brasileiras. Há uma carência muito grande de recursos nessa área, sendo poucos os materiais e livros. Por esse motivo, esperamos que o MEC seja receptivo em relação às críticas e sugestões apresentadas, para que a divulgação do Referencial possa realmente contribuir para uma significativa melhoria da qualidade da educação infantil no país (ANPED, 1998, p. 96).

Mas, para Kuhlmann Jr. (2007), a forma como o documento foi elaborado, priorizando a disciplinarização, traz prejuízo à criança pequena que não está preparada para os níveis de concentração que lhe são impostos. 0 autor aponta, em outra discussão sobre o RCNEI, que ainda “[...] não é o momento de sistematizar o mundo para apresentá-lo à criança: trata-se de vivê-lo, de proporcionar-lhe experiências ricas e diversificadas" (KUHLMANN JR., 2005, p. 57).

Quanto à ideia de disciplinarização para a El, também Cerisara (2002) faz críticas ao modelo apresentado no RCNEI, ao afirmar que

Esta forma de organização e o conteúdo trabalhado evidenciam uma subordinação ao que é pensado para o Ensino Fundamental e acabam por revelar a concepção primeira deste RCNEI, em que as especificidades das crianças de 0 a 6 anos acabam se diluindo no documento ao ficarem submetidas à versão escolar de trabalho (CERISARA, 2002, p. 337).

Com essas críticas, os autores apontam a contradição presente no documento quanto à concepção de educação infantil em que se estabelece a criança como centro da proposta, numa perspectiva de uma educação humanizadora, na qual as crianças devam ter experiências ricas e um desenvolvimento integral, mas com a ideia de currículo centrada em áreas de ensino de disciplinas específicas, remetendo à disciplinarização.

Além das questões curriculares, outros pontos relativos à concepção de escola que o documento apresenta foram criticados, como a de uma escola idealizada, distante da realidade brasileira. Nessa proposta curricular 
não foram apontados os problemas que a educação infantil enfrentava no momento de sua elaboração, como o atendimento em espaços precários, por vezes insalubres. $E$, ainda, a complexidade do texto não considerou a fraca formação dos profissionais da maioria desses estabelecimentos. Esses questionamentos têm sido alvos de contestações sobre a estrutura do RCNEl, como a de Palhares e Martinez (199933, p. 10 apud CAMPOS, 2002, p. 6), ao relatar que

O RCNEI é estruturado como se esses problemas não fizessem parte do cotidiano das instituições de educação infantil. O conteúdo, as recomendações "didáticas" presentes no documento remetem: "[...] àquela infância desejada, rica em estímulos, pertinente quanto à adequação do vínculo do educador com a criança, e vai nos seduzindo, transportando, remetendo para a criança idealizada, ele nos afasta da realidade da maioria das creches brasileiras, desconhecendo ou ocultando parte dos conhecimentos anteriormente sistematizados e divulgados.

Além disso, com a necessidade de cumprir uma agenda política, o MEC ignorou o processo de discussão que vinha ocorrendo no Brasil sobre este nível de educação, tendo como resultado um aglomerado de propostas, teorias e modelos curriculares que não refletem a realidade da educação infantil brasileira.

Embora os objetivos presentes no documento apontem para uma educação menos sistemática e mais voltada para oportunizar experiências e vivências à criança pequena, essa ideia se confunde com uma listagem complexa e extensa de conteúdos que devem ser trabalhados. Nesse contexto, a concepção de uma educação infantil centrada na criança se dilui no excesso de conteúdos e de orientações que remetem a um ensino fragmentado e com ênfase na pré-escolarização, cujo interesse parece se direcionar para o desempenho da criança, como nos outros níveis de educação.

Em relação à divulgação do RCNEI, é interessante notar que, embora as pesquisas realizadas por MEC e UFRGS (2009), Wiggers (2009) e Francisco (2010) indiquem que o documento é o mais utilizado nas escolas de educação infantil do país, Silva (2013) constatou em pesquisa realizada em escolas municipais de educação infantil que o documento é apontado somente como orientador da organização do texto do projeto pedagógico. Ele está presente no documento escrito da escola, por exigência legal, mas não é utilizado na orientação do trabalho docente.

3 PALHARES, M. S.; MARTINEZ, C. M. S. A educação infantil: uma questão para o debate. In: FARIA, A. L. G.; - (Orgs.). Educação infantil pós-LDB: rumos e desafios. Campinas: Autores Associados-FE/Unicamp; São Carlos: Ed. UFSCAR; Florianópolis: Ed. UFSC, 1999. 
PARA PENSAR...

Apesar das críticas e questionamentos que se fazem sobre as questões relacionadas à educação infantil, é possível observar os avanços que ocorreram ao longo da história, não tão rápido como se desejaria, mas em processo, como se almeja. Quem viveu essa transição é capaz de avaliar quanto se conquistou e ter esperança de que mais vitórias estão por vir.

É preciso, no entanto, levar em consideração que este nível de educação ainda está sendo constituído. Sua denominação como etapa inicial da educação básica é muito recente (1996) e suas especificidades ainda estão sendo trabalhadas no meio escolar, pois a atenção à criança pequena em instituições públicas ou privadas nasceu com uma função social e não educacional.

Somente a partir da década de 1970 o cunho educacional ganha força, impulsionado pelos estudos acadêmicos, com a chamada proposta de educação compensatória. Esta proposta de educação compensatória dá origem às instituições educacionais públicas municipais em São Paulo, denominadas Escolas Municipais de Educação Infantil (Emei), num atendimento que visava suprir as "carências" culturais e deficiências na aprendizagem de crianças das classes operárias, que tinha como objetivo a diminuição da evasão e da repetência escolar. Tal modelo trouxe para a educação da época um caráter preparatório para os outros níveis de ensino, que insiste em se manter vivo nos meios escolares, no qual "constata-se uma força resistente à mudança, apegada a formulações específicas da prática pedagógica de tendência escolarizante [...]" (SOUZA, 2012, p. 194).

Ainda estão se trilhando os caminhos para a descoberta de potencialidades que este nível de educação apresenta, considerando, principalmente, a criança como o sujeito de direitos e, como tal, exigindo-se que se ofereça a ela uma escola de qualidade, onde se garanta o espaço não só para o ensino, mas para o brincar e o cuidar, inerentes ao seu processo de desenvolvimento.

O maior desafio que se apresenta neste momento parece ser o de separar o caráter assistencialista impregnado nas escolas que atendem essas crianças, sobretudo as que recebem crianças de 0 a 3 anos. A valorização de quem trabalha com essa faixa etária, mostrando que a atenção dedicada a ela é tão importante quanto em qualquer outro nível de educação, deve ser considerada. 
0 interesse pelo desempenho escolar tem direcionado grande parte das políticas públicas e trabalhos acadêmicos. Felizmente, é preciso ressaltar que tem aumentado o número de pesquisas realizadas com esta modalidade de educação.

Mas é primordial que a formação inicial desses educadores nas universidades leve em conta as especificidades desta faixa etária e ofereça mais subsídios para sua vida profissional. Mas isso já é assunto para outro artigo... 


\section{Infant education in Brazil: development and challenges over history}

Abstract: This article presents a historical survey of education for children under school age in Brazil, approaching both public policies for early childhood and popular and private initiative movements. Moreover, to understand the reasons of the dichotomy between the Centro de Educação Infantil (CEI) and the Escola Municipal de Educação Infantil (EMEI in São Paulo, Brazil), it is necessary to know how each of them is constituted before their combination in the same Education System. Therefore, we used official documents and the relevant literature. Our purpose was to describe the historical evolution and the disputes and consensus produced by the government, civil society and academe.

Keywords: Infant Education. Child. Public Policies. Education. 


\section{REFERÊNCIAS}

ANPED. Parecer sobre o documento Referencial Curricular Nacional para a Educação Infantil. Revista Brasileira de Educação. São Paulo, n. 7, p. 8996, jan./fev./mar./abr. 1998. Disponível em: 〈http://www.anped.org.br/rbe/ rbedigital/rbde07/rbde07_09_espaco_aberto_ anped.pdf $\rangle$. Acesso em: 10 abr. 2012.

ARAÚJO, E. S. Matemática e infância no Referencial Curricular Nacional para a Educação Infantil: um olhar a partir da teoria histórico-cultural. Zetetiké. Campinas: Faculdade de Educação, Unicamp, v. 18, n. 33, jan./jun. 2010.

BARRETO, A. M. R. F. Situação atual da educação infantil no Brasil. In: BRASIL, Ministério da Educação e Cultura. Subsídios para credenciamento e funcionamento de instituições de Educação Infantil. Brasília: MEC/SEF, v. 2, p. 23-34, maio 1998. Disponível em: 〈http://portal.mec.gov.br/seb/arquivos/ pdf/volume_II.pdf〉. Acesso em: 14 dez. 2012.

BRASIL. Ministério da Educação; TV ESCOLA. Referencial Curricular Nacional para a Educação Infantil. Disponível em: 〈http://www.youtube.com/watch?v= a33Ej_huuFA>. Acesso em: 14 ago. 2012.

- Ministério da Educação. Secretaria da Educação Básica; UNIVERSIDADE FEDERAL DO RIO GRANDE DO SUL. Práticas cotidianas na Educação Infantil: bases para a reflexão sobre as orientações curriculares. Projeto de cooperação técnica MEC e UFRGS para construção de orientações curriculares para a Educação Infantil. Brasília, 2009.

- Ministério da Educação. Secretaria de Educação Fundamental. Referencial Curricular Nacional para a Educação Infantil. Brasília: MEC/SE, v. 1, 2 e 3, 1998.

. Lei n. 9.394, de 20 de dezembro de 1996. Estabelece as diretrizes e bases da educação nacional. Brasília, 1996.

. Lei n. 8.069, de 13 de julho de 1990. Dispõe sobre o Estatuto da Criança e do Adolescente e dá outras providências. Brasília, 1990.

Constituição. Constituição da República Federativa do Brasil de 1988, de 5 de outubro de 1988. Brasília: 1988.

Conselho Nacional de Educação, Câmara de educação básica. Resolução n. CEB 01/99, 07 de abril de 1999, institui as Diretrizes Curriculares 
Nacionais para a educação infantil. Disponível em: 〈http://portal.mec.gov.br/ cne/arquivos/pdf/ CEB0199.pdf`. Acesso em: 17 jun. 2012.

CAMPOS, M. M. A regulamentação da Educação Infantil. In: BRASIL. Ministério da Educação e do Desporto. Subsídios para credenciamento e funcionamento de instituições de Educação Infantil. Brasília: MEC/SEF, v. 2, p. 35-64, maio 1998. Disponível em: 〈http://portal.mec.gov.br/seb/arquivos/ pdf/volume_ II.pdf〉. Acesso em: 14 dez. 2012.

. A mulher, a criança e seus direitos. Cadernos de Pesquisa, n. 106, p. 117-127, mar. 1999.

CAMPOS, M. M. (Org.) et al. A contribuição da educação infantil e seus impactos no início do ensino fundamental. Educação e Pesquisa. São Paulo: v. 37, n. 1, p. 15-33, jan./abr. 2011 a.

CAMPOS, M. M. (Org.) et al. A qualidade da educação infantil: um estudo em seis capitais brasileiras. Cadernos de Pesquisa. Campinas: Autores Associados, v. 41, n. 142, p. 20-54, jan./abr. 2011b.

CAMPOS, R. Políticas governamentais e educação infantil: histórias ou estórias? Zero-a-Seis, Revista eletrônica, UFSC, n. 5, p. 21-31, jan./jul. 2002.

CERISARA, A. B. A produção acadêmica na área da educação infantil com base na análise de pareceres sobre o Referencial Curricular Nacional da Educação Infantil: primeiras aproximações. In: FARIA, A. L. G.; PALHARES, M. S. (Org.). Educação Infantil pós-LDB: rumos e desafios. 5. ed. Campinas: Autores Associados, 2005. p. 19-50.

- Referencial Curricular Nacional para a Educação Infantil no contexto das reformas. Educação \& Sociedade, Campinas, v. 23, n. 80, p. 326-345, set. 2002.

CURI, A.; MENEZES FILHO, N. A. A relação entre educação pré-primária, salários, escolaridade e proficiência escolar no Brasil. São Paulo, 2006. Disponível em: 〈http://www.scielo.br/pdf/ee/v39n4/05.pdf=>. Acesso em: 20 jul. 2012.

FILÓCOMO, D. A gênese da educação especial: a contribuição dos parques infantis da cidade de São Paulo: 1947 a 1957. 2005. 107f. Dissertação (Mestrado em Educação) - Universidade São Francisco, Itatiba, 2005.

FRANCISCO, S. dos S. A. Análise de Planos de Ensino de Educação Infantil, 
à luz de uma literatura analítico-comportamental. 2010. 85f. Dissertação (Mestrado em Educação: Psicologia da Educação) - Pontifícia Universidade Católica de São Paulo, São Paulo, 2010.

HADDAD, L. O Referencial Curricular Nacional para a Educação Infantil no contexto das políticas para a infância: uma apreciação crítica. In: REUNIÃO ANUAL DA ANPED, 22., 1998, Caxambu. Anais... Caxambu: Universidade Federal de Santa Catarina, 1998. Disponível em: 〈http://www.ced.ufsc.br/ nee0a6/anped.html〉. Acesso em: 14 jun. 2012.

KRAMER, S. Propostas pedagógicas ou curriculares de educação infantil: para retomar o debate. Caxambu, 1999, p. 1-22. Disponível em: 〈http://www. ced.ufscar.br/ neeoa6/ tsoniak.pdf〉. Acesso em: 22 out. 2012.

As crianças de 0 a 6 anos nas políticas educacionais no Brasil: Educação Infantil é fundamental. Educação \& Sociedade, Campinas, v. 27, n. 11, p. 797-818, out. 2006.

KUHLMANN JR., M. Entrevista: Menos assistencialismo, mais pedagogia. Difusão de Ideias, São Paulo, FCC, p. 1-8, maio 2007. Disponível em: 〈http://www.fcc.org.br/ conteudosespeciais/difusaoideias/pdf/entrevista_ educacao_infantil.pdf $\rangle.$ Acesso em: 14 fev. 2012.

Educação infantil e currículo. In: FARIA, A. L. G.; PALHARES, M. S. (Org.). Educação infantil pós-LDB: rumos e desafios. 5. ed. Campinas: Autores Associados, 2005, p. 51-66.

PALHARES, M. S.; MARTINEZ, C. M. S. A educação infantil: uma questão para o debate. In: FARIA, A. L. G.; PALHARES, M. S. (Org.). Educação infantil pós-LDB: rumos e desafios. 5. ed. Campinas: Autores Associados, 2005, p. 5-18.

SILVA, S. O. A. Políticas da educação infantil e o ensino da matemática. 2013. 104f. Dissertação (Mestrado em Educação: Psicologia da Educação) Pontifícia Universidade Católica de São Paulo, São Paulo, 2013.

SOUZA, I. G. C. Subjetivação docente: a singularidade constituída na relação entre o professor e a escola. 2012. 223f. Tese (Doutorado em Educação: Psicologia e Educação) - Universidade de São Paulo, São Paulo, 2012.

TAGGART, B. et al. O poder da pré-escola: evidências de um estudo longitudinal na Inglaterra. Cadernos de Pesquisa. São Paulo, FCC, v. 41, n. 142, p. 68-99, jan./abr. 2011. 
WIGGERS, V. Aportes teóricos e metodológicos que subsidiam as orientações curriculares na educação infantil. In: REUNIÃO ANUAL DA ANPED, 32., 2009, Caxambu. Anais... Caxambu: Hotel Glória, 2009. Disponível em: 〈http://www. anped.org.br/reunioes/32ra/arquivos/trabalhos/GT07-5406--Int.pdf〉. Acesso em: 25 out. 2012.

RECEBIDO: Maio de 2014.

APROVADO: Setembro de 2014. 